\title{
Mediastinal Hydatid Cyst: Exceptional Location
}

\author{
Mountassir Moujahid1 ${ }^{*}$, Issam Ennafaa², Ahmed Ghari², Issam Raissouni ${ }^{3}$, \\ Karim Nadour ${ }^{1}$, Moulay Hassan Tahiri ${ }^{1}$ \\ ${ }^{1}$ Departement of Surgery, 5th Military Hospital, Guelmim, Morocco \\ ${ }^{2}$ Departement of Radiology, 5th Military Hospital, Guelmim, Morocco \\ ${ }^{3}$ Departement of Reanimation, 5th Military Hospital, Guelmim, Morocco \\ Email: ${ }^{\text {m.moujahid@gmx.fr }}$
}

Received 5 December 2013; revised 5 January 2014; accepted 12 January 2014

Copyright (C) 2014 by authors and Scientific Research Publishing Inc.

This work is licensed under the Creative Commons Attribution International License (CC BY).

http://creativecommons.org/licenses/by/4.0/

(c) () Open Access

\section{Abstract}

The hydatid disease establishes a real problem of public health in our country. The hydatid cyst is preferentially located at the level of the liver and the lungs. Its mediastinal location is extremely rare, representing 0 à $4 \%$ of all the hydatic locations. The imaging plays an important role in the diagnosis of this affection and in the balance sheet of extension in search of another location. The hydatid cyst also raises a diagnostic problem with the cystic hurts of the mediastinum. We report a case of mediastinal hydatid cyst colliged in the service of general surgery at the 5th military hospital.

\section{Keywords}

Hydatid Cyst; Mediastinal; Diagnosis and Treatment

\section{Introduction}

It is the cosmopolitan antropozoonose which raises a real problem of the public health. The mediastinum localization of the hydatid cyst is extremely rare representing $0 \%$ to $4 \%$ of all the hydatic localizations. It raises gladly a delicate diagnostic problem with the cystic hurts of the mediastinum.

We report a case of mediastinum hydatid cyst collaged in the general surgery service at the 5th Military Hospital.

\section{Observation}

It was about a 48-year-old man, without particular pathological histories, living in rural areas presenting the no-

${ }^{*}$ Corresponding author. 
tion of contact with dogs, who accused a dyspnoea with chronic cough evolving for six months in an apyretic context and a preservation of the general state. The lung radiography objectified a mediastinal extension.

The thoracic scanner showed a voluminous cystic mass interesting the retro sternal previous mediastinum prevascular meadow in fine wall, in regular limit and homogeneous contents without partitions nor vegetations intra cystic. It presents an intimate contact with the big vascular trunks but with the net interface, in seen report the clinical context with a hydatid cyst (Figure 1).

The biological balance showed a sedimentation speed raised to $34 \mathrm{~mm}$ at first hour associated with a hyper eosinophilia. The hydatid serology was negative; a preoperative abdominal echograph in search of a second localization was normal. The surgical operation was realized by a sternotomy allowing to treating the hydatid cyst by a peri cystectomy. The follow-up were simple. No case of second recurrence on a backward movement of two years.

\section{Discussion}

The mediastinal localization of the hydatidosis is extremely rare; the incidence is from 0 to $4 \%$ of all the visceral localizations. It does not exceed $0.1 \%$ in the western countries .the mediastinum hydatid cyst represent $4 \%$ of all the mediastinal masses in the countries of hydatic endemic disease [1]. They are the privilege of the young adult, without ascendancy of sex.

Two mechanisms can be at the origin of this localization, the parasite having exceeded the hepatic and lung filters penetrates into the systematic circulation and can settle in the mediastinum. The second mechanism is the one of a progress by lacteals and lymphatic ways [2].

The clinical symptom is not specific, dominated by signs of compression. All the localizations in the mediastinum are possible with a preference for the posterior mediastinum [1] [3].

Hydatid cysts of the posterior mediastinum can entail pains and neurological signs with possibility of erosion of ribs and vertebras. Hydatid cysts of the average mediastinum, sitting in the basis of the heart or at the level of the stick can provoke a fatal bleeding by vascular erosion. Hydatid cysts of the previous mediastinum can entail a tracheal compression or superior cellar and sometimes invade the pericardium. Cardio phrenic hydatid cysts show themselves by a syndrome of cardiac tumor and can break in the cardiac cavities [4] [5].

The hydatic serology is fundamental, sometimes allowing to assert the diagnosis [2] [4] [6]. The standard radiography of lung shows a mediastinal extension associated or not to a cardiomegaly, the calcifications of the wall observing during primitive hydatid cyst of the mediastinum, they represent a not insignificant diagnostic argument, but they remain rare [6].

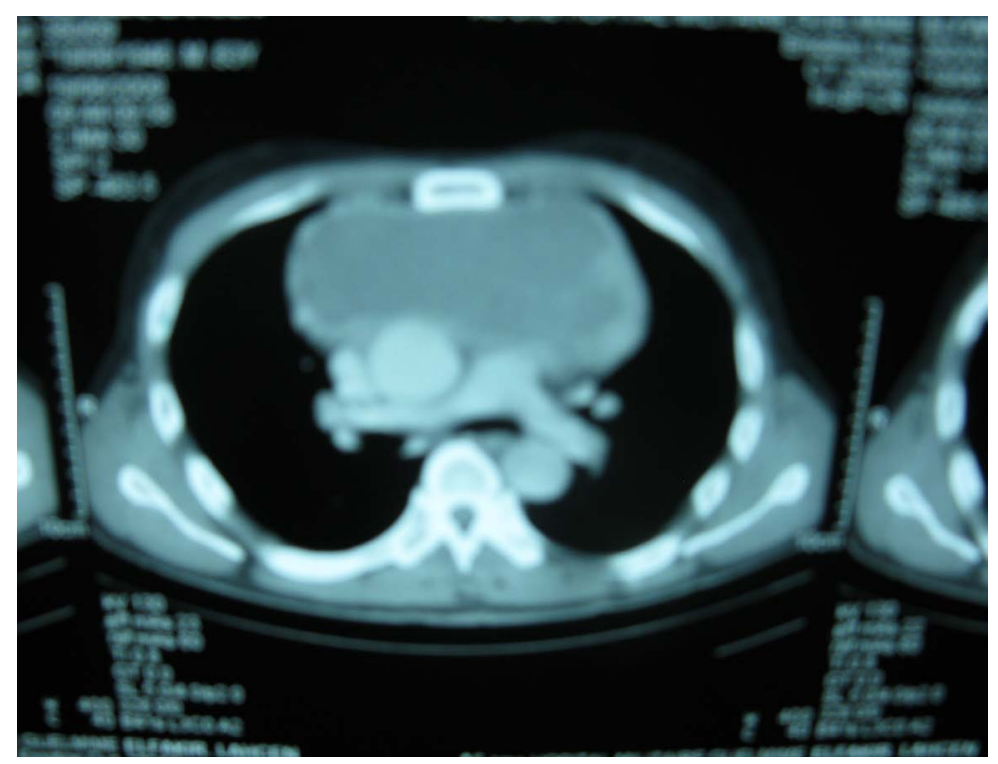

Figure 1. Thoracic scanner showing a cystic formation of the retro sternal previous mediastinal and the vascular meadow. 
The thoracic echograph practiced for hydatid cysts close to the wall, to the diaphragm and intra cardiac, is a very successful examination, because it allows to recognize the liquid character and the fine wall of the cyst and to specify the topography. The image of a solid "little spherical bell" within the liquid, within the unsticking of membrane or of vesicles girls, is strongly suggestive of the diagnosis, but rarely observed [6] [7]).

The echograph also allows to specify the existence of an effusion. The magnetic resonance imaging [1] [4] [8]-[10] is little used in this localization. It will bring certainly useful information for the positive diagnosis of the hydatid cyst of the mediastinum, in particular in the difficult cases, by detecting vesicles girls or floating membranes inside the hydatid cyst. It will also allow specifying better the topography of these hurts and the reports with the organs of neighborhood. It is also interesting in the cardiac localization.

In country of endemic disease, the diagnosis bases essentially on the clinic exam and the scanner. In the countries where the hydatidosis is rare, the diagnosis will make discuss the other cystic hurts of the mediastinum [10]-[14] in particular the bronchogenic cyst which is generally attached to the bronchial tree and presents a thick wall with a thick contents, of density spontaneously high, not enhancing after contrast.

With the enteric cyst of posterior seat with the contact of the esophagus, the variable density is according to the contents and is in relatively thick wall. This cyst is mostly associated with vertebral anomalies.

With the lymphangioma cyst which is more frequent at the child's of mostly cervical seat with generally a mediastinal extension. The hurt is multi-compartmentalized, among which the wall and the partitions raise after injection of contrast.

And with the pleuro pericardiac cyst which is translated by a mass of liquid density without recognizable wall of triangular aspect and sharp at the level of the part with a pericardiac attach what is an argument in favour of the diagnosis.

\section{Conclusion}

The mediastinal localization of the hydatid cyst is rare. The imaging presents a double interest within the framework of the hydatidosis that of the positive diagnosis by making a fine analysis of the radiological images and their report with the organs of neighborhood, and the balance assessment of extension in search of extra mediastinum hydatid localization.

\section{References}

[1] El Abbassi Skalli, A., El Amraoui, F., Chikhaoui, N., et al. (2000) Mediastinal Hydatid Cyst Two Cases. Journal of Radiology, 81, 154-157

[2] Vonsinner, W.N., Linjaw, T. and Alwatban, J.A. (1990) Mediastinal Hydatid Disease; Report of three Cases. Canadian Association of Radiologists Journal, 41, 79-82.

[3] Benzarti, M., Jerray, M., Khirouni, S. et al. (1997) Primitif Mediastinal Hydatid Calcified Compressif Cyst. Review of Respiratory Disease, 14, 53-54

[4] Mohd, S., Rakesh, B., Zuber, A., et al. (2006) Mediastinal Hydatid Cyst Rupturing into the Pleural Cavity Associated with Pneumothorax: Case Report and Review of the Literature. Canadian Respiratory Journal, 13, 211-213.

[5] Ben Mustapha, A., Ben Hamadi, F., Bouziane, A., et al. (1992) Thoracic Extralung Hydatic Cyst. Medicine Tropical, 52, 399-405.

[6] Charon, P., Hamwi, A., Beroud, P., et al. (1993) Mediastinal Hydatid Cyst Interest of the Current Methods of Medical Imaging. Sem Hôp Paris, 69, 100-103.

[7] Khannous, M., Ferreti, G., Ranchoup, Y., et al. (1993) Intrathoracic Hydatidosis Contribution of the TDM (25 Observations). Journal of Radiology, 74, 541-548.

[8] Trigano, J., Mourot, F., Talmoudi, T., et al. (1985) Semiology of the Hydatic Cyst of the Heart. Study of a Series of 13 Cases and Interest of the Scanner. Archives des Maladies du Coeur et des Vaisseaux, 78, 1895-1899.

[9] Marti-Bonmati, L., Touza, R. and Montes, H. (1988) CT Diagnosis of Primary Mediastinal Hydatid Cyst Rupture into the Aorta: A Case Report. CardioVascular and Interventional Radiology, 11, 296-299. http://dx.doi.org/10.1007/BF02577040

[10] Desnos, M., Bruchet, E. and Cristofi, P. (1987) Polyvisceral Echinococcosis with Cardiac Involvement Imaged by Two Dimensional Echography, Computed Tomography, Nuclear Magnetic Resonance Imaging. American Journal of Cardiology, 59, 383-384. http://dx.doi.org/10.1016/0002-9149(87)90828-9

[11] idi, A., Zannad-Hantous, S., Mestiri, I., et al. (2006) Primitif Mediastinal Hydatid Cyst: 14 Cases. Journal of Ra- di- 
ology, 12, 1869-1874.

[12] Karnak, I., Ciftci, O.A. and Tanyel, C.F. (1998) Hydatid Cyst: An Unusual Etiology for a Cystic Lesion of the Posterior Mediastinum. Journal of Pediatric Surgery, 33, 759-760. http://dx.doi.org/10.1016/S0022-3468(98)90211-1

[13] Oguzkaya, F., Akcali, Y., Kahraman, C., et al. (1997) Unusually Located Hydatid Cysts: Intrathoracic But Extrapulmonary. The Annals of Thoracic Surgery, 64, 334-337. http://dx.doi.org/10.1016/S0003-4975(97)00521-3

[14] Aloui-Kasbi, N., Chennoufi, F., Boussetta, K., et al. (2004) Mediatinal Hydatic Cyst a New Observation. Journal de Pédiatrie et de Puériculture, 17, 312-315. 